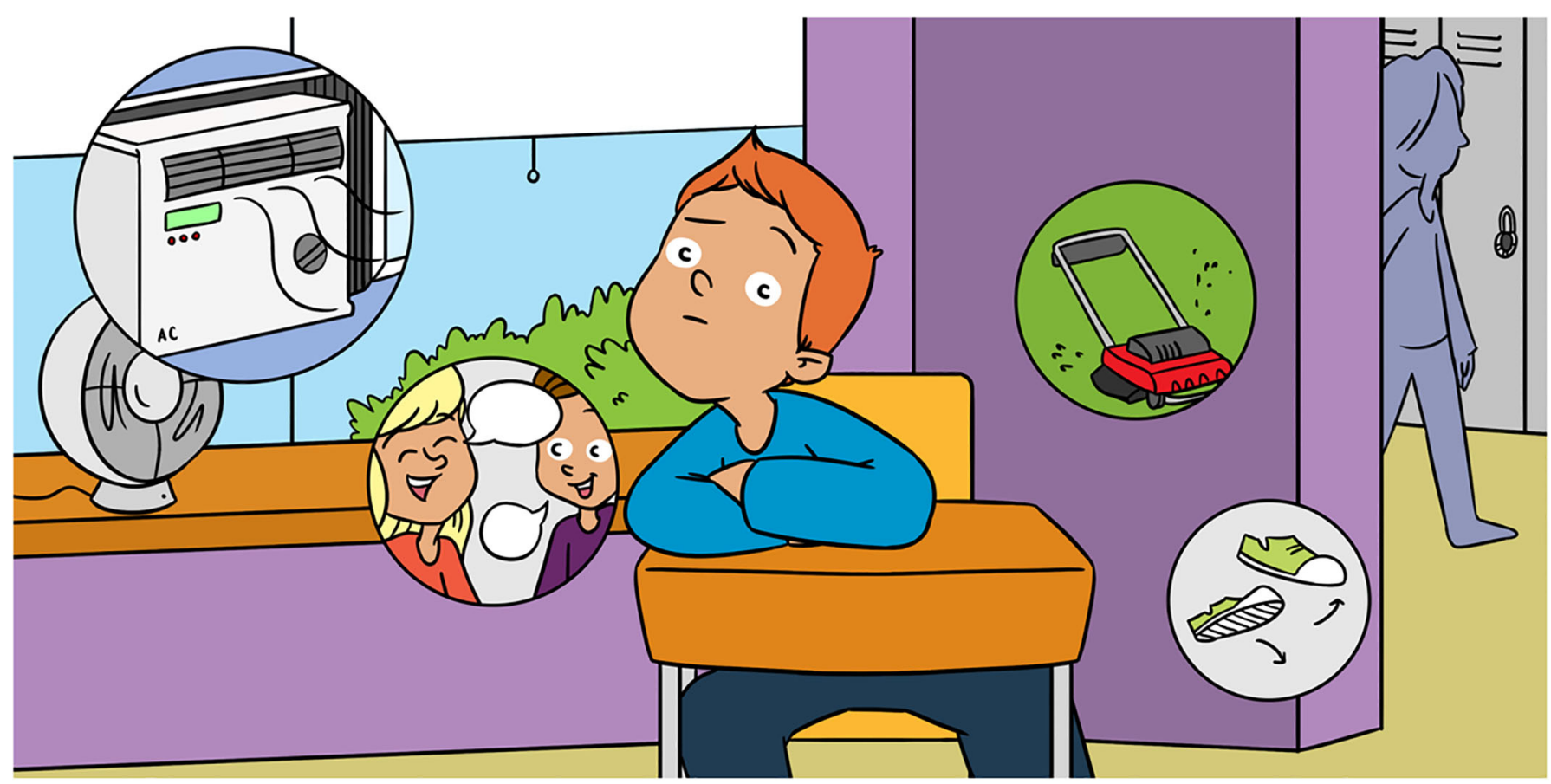

\title{
WHEN CHOOSING NOT TO LISTEN HELPS YOU HEAR AND LEARN
}

\section{Angela M. AuBuchon ${ }^{1 *}$ and Ryan W. McCreery ${ }^{2}$}

${ }^{1}$ Working Memory and Language Laboratory, Boys Town National Research Hospital, Omaha, NE, United States

${ }^{2}$ Audibility, Perception and Cognition Laboratory, Boys Town National Research Hospital, Omaha, NE, United States

\section{YOUNG REVIEWERS:}

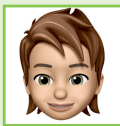

IAGO

AGE: 13

ROADRUNNERS

\& COBRAS

AGES: 10-11

\section{AUDITORY SYSTEM}

The body system responsible for hearing It includes

machine-like pieces and neurons which carry information about sound from the ear to the brain.
Listening to important sounds will help us learn. However, it can be hard to separate the important sounds from the not-so-important sounds, or noise. Different parts of our brains are impacted by different kinds of noise, making it hard to learn. As our brains grow, we get better at separating the important sounds from the noise. However, there are a few listening tricks that both children and adults can use to listen and learn in noise.

Adults often expect children to learn in noisy classrooms. Chairs scrape across the floor. Lawn mowers cut grass outside. Other students talk at the next table. In fact, we recently measured sounds in 157 classrooms; even with no students in the room, 137 classrooms had enough noise to interfere with listening [1]! It might seem like a short trip for sounds to travel from our ears to our brains. Still, there are many ways for noise to disrupt learning along the way. What can be especially frustrating is that sometimes noises do not bother adults as much as they bother kids. This is partly because a child's auditory system is still growing and changing (Figure 1). Also, adults have skills 
Figure 1

Here we see the machine-like structures and neurons of the auditory system. The parts most involved in hearing and ignoring noise are labeled. The pinna funnels sounds into the ear canal. We should look at important sounds because the pinna is best at funneling sounds in front of us. The cochlea turns sounds into electricity which travels down the auditory nerves to meet in the brainstem. Then electric signals travel through the thalamus on their way to auditory cortex in the temporal lobe of the brain.

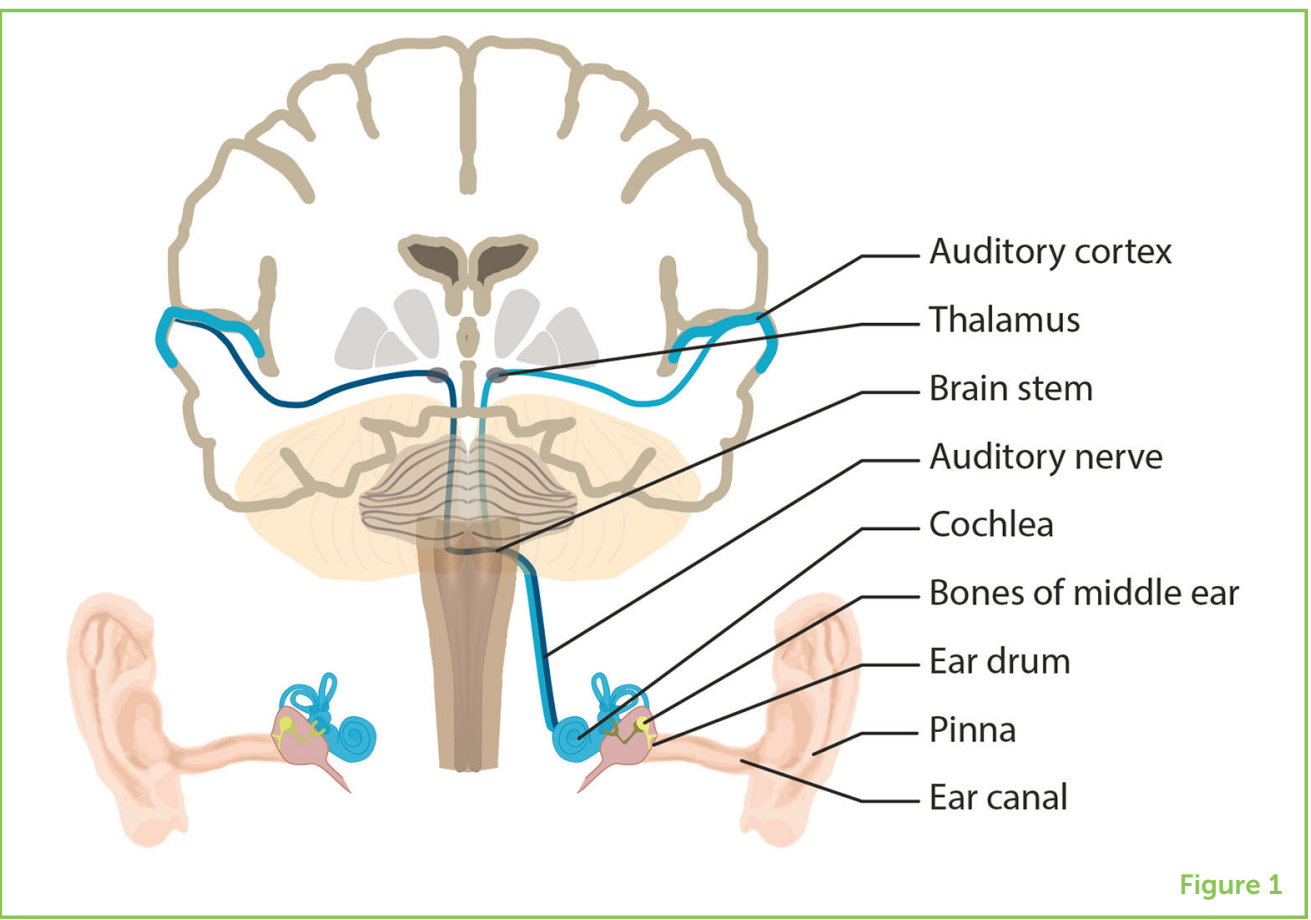

for dealing with noise. We will discuss how sounds that do not seem important still make it hard to understand other things we hear and see. Then we will give you tricks for listening and learning through the noise.

\section{CATEGORIES OF NOISE}

Different noises affect our auditory system in different ways. We will focus on three kinds of noise. First, there is noise that changes over time. This would be the kind of noise from two of your classmates having a conversation. Another example of changing noise would be listing to jazz music while you are studying. When noise changes, sometimes the noise has a high pitch, like a trumpet; sometimes, it has a low pitch like a tuba. Sometimes the noise is loud and sometimes it is quiet. We measure the loudness of sounds in decibels (dB). Soft sounds, like leaves rustling, are around $20 \mathrm{~dB}$, and loud sounds like airplane engines are over $100 \mathrm{~dB}$. Second, there is steady noise. This is noise that sounds mostly the same from start to finish. This type of noise includes the whirring of a computer, the roar of a lawn mower, and the babble in the cafeteria as everyone talks at once. The third type of noise is sudden and short. Noises in this category are often surprising. These noises might be loud like a slamming door, but they do not have to be loud. They just need to be louder than nearby sounds. A softly buzzing cell phone would be in this category if the rest of the room were very quiet. 
PINNA (PLURAL:

PINNAE)

The part of the auditory system attached to the outside of the head, and what people usually call the "ear." Scientist call everything from the pinna to cochlea the "ear."

COCHLEA (PLURAL: COCHLEAE)

A spiral-shaped structure that turns sound waves into nerve signals that leave the cochlea on the Auditory Nerve-one of 12 special "cranial nerves" that bypass the spinal cord.

\section{SEPARATING SOUNDS FROM NOISE}

When one place has many sounds, those sounds mix together as they travel to our ears. Your "ears" are more than those curvy soundwave-catchers on the sides of your head which are called the pinnae. Each of your ears also includes the ear canal to your ear drum, your ear drum, some very small bones on the other side of your ear drum, and a structure called the cochlea. The cochlea is where sound waves turn into signals that neurons in your auditory system understand. The cochlea is also one place sounds mix together. Imagine that your cochlea is like a pond. The sounds coming into your cochlea are like rocks leaving ripples as they are thrown into the pond. If every student in the cafeteria tossed rocks into our pond, there would be ripples everywhere. Eventually, the ripples would run into each other. After the ripples get mixed up, it is hard to pick out exactly which ripples came from which students. This is the first reason it is hard to learn when it is noisy: two sounds are not very good at being in the same place at the same time. Instead, two sounds will mix into one messy, confusing sound. All three kinds of noise mix with important sounds, but steady noises mix with other sounds the most. Unlike sudden noises, steady noise lasts for a long time. Unlike changing noise, steady noise never gets quieter. When changing noise gets quiet, even for just a moment, the important sound has the cochlea all to itself. One trick is to use those moments of quiet to "glimpse" the important sound. Our cochleae are fully developed before we are born, so sounds mix in the cochleae the same for adults and children. However, adults are better able to use tricks like "glimpsing" to hear important sounds. This is because our brains' ability to process sounds gets better as we get older.

In order to make sense of what is happening around us, we need to divide the mixed sounds back into separate bits. A trick to help us separate sounds is to make the important sound louder. Imagine our pond full of ripples from the students' rocks. Now, imagine your teacher throwing in a huge boulder. The boulder's ripples might still mix with the ripples from the students' rocks. However, the boulder's ripples are so big they are easy to separate. We invited children with typical hearing and children with hearing loss to listen to important sentences in background noise. Very few children in either group could understand the sentences when the sentences were quieter than the noise or when the sentences and the noise were the same loudness. As soon as the sentences became even a few decibles louder than the noise, most children with typical hearing were able to separate sounds from noise and understand the sentences. However, some children needed the sentences to be much louder than the noise in order to separate them (Figure 2).

Making the important sounds louder is a useful trick because there are lots of ways to make your teacher louder. You could ask your teacher to raise his voice, or you could move closer to your teacher. 
Figure 2

Very few children understand half of what they hear when the talker is quieter than the noise. For example, the bottom of the graph would be like the teacher talking (most people talk at about 60 dB) next to a lawn mower (70 dB). A noisy classroom is about 90 $\mathrm{dB}$ ! Most children with typical hearing need the talker to be at least as loud as the noise (right side). Children near the top of the graph need the talker to be louder than the noise. Notice that almost all children with hearing loss are near the top of the graph (left side). This illustrates how much harder listening in noise is for children with hearing loss-even when they use hearing aids [6].

\section{HABITUATION}

A decrease in responding when the same sound, sight, smell, or touch is presented for a long time.

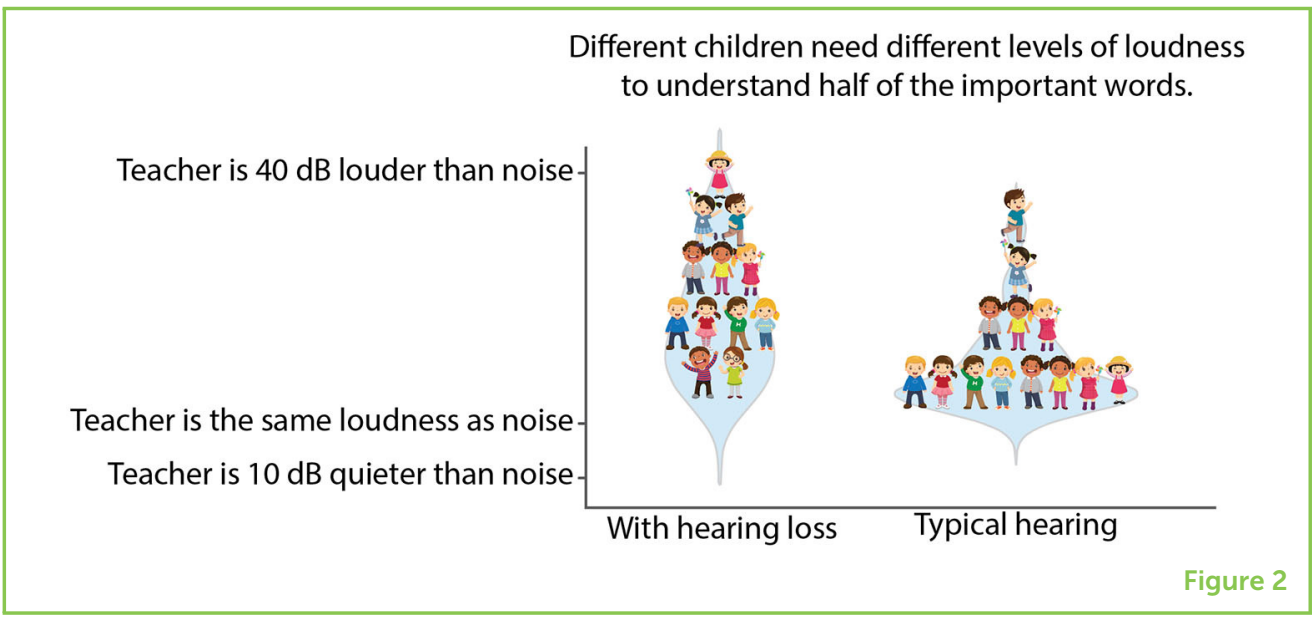

You could also try to make the noise quieter. If the noise is outside, ask to close the window. Our brains also have a useful trick for making the not-so-important noises seem quieter. This trick is called habituation. Habituation is when the same thing is presented over and over and we stop responding to it. Habituation occurs for sounds, sights, smells, and touches. Have you ever made popcorn that smelled really good? After a while, you stopped noticing the smell. Then you went to the bathroom, and when you came back, you could smell your popcorn again. This is an example of habituation to a smell. The popcorn smell is still there, but your brain stopped noticing it. The same thing can happen with sounds-especially steady noises. Even though the steady noise does not actually get quieter, it produces a smaller brain response over time which makes the important sound seem louder in comparison. Unfortunately, even children as old as 9-11 years take longer than adults to habituate to sounds [2]. Adults' ability to habituate to steady noises may be one reason that they are better than children at understanding important words even when there is noise [3].

We also separate sounds by figuring out where each sound is coming from. This is possible because we have two ears. A sound on your right will be a tiny bit louder to your right ear than your left ear (Sound Demo). A sound on your right will also get to your right ear just a tiny bit faster than it gets to your left ear. The difference is so small (half of one millisecond) that you would not ever notice it. Your auditory system notices, though! After sound information leaves each cochlea, it travels along a special nerve called the auditory nerve directly to the brainstem. The brainstem gets nerve signals from both cochleae and can tell which cochlea heard a sound first and louder. By the time we are adults, our brainstems have figured out exactly how much more time it takes (and how much the loudness changes) as sound travels around our heads. Our heads are still growing very quickly until we are 6 years old, which makes finding sounds harder for very young children. Knowing where each sound comes from helps our auditory system unmix sounds. 


\section{THALAMUS}

A structure deep inside the brain that sends information about sound, sight, taste, and touch to the rest of the brain. It may alert our brains to changes in our surroundings.
We can also separate mixed sounds is by paying attention to one sound while ignoring the other sounds. We do not entirely understand how our brains are able to do this. Sometimes, we seem to decide what we pay attention to, but other times it seems like our brains decide for us. If your class was working when a door suddenly slamed, the students would look at the door. Your auditory system heard the sound, figured out where it was coming from, and decided it might be important enough to pay attention to. One idea is that the thalamus, a structure deep inside the brain, helps prioritize information [4]. The thalamus gets information about sounds as well as sights, tastes, and touch. The thalamus can monitor our environment and detect when a sound, sight, or touch changes. Sounds are more likely to get our attention if they come on or change unexpectedly. This means that changing sounds might get our attention even when we do not want them to.

\section{NOISE MAKES IT HARD TO LEARN WHAT WE SEE}

Not only does noise make it difficult to pay attention to important sounds, but noise also makes it difficult to pay attention to important information we see. Until children are about 9 years old, even steady noises, like air conditioners, can hurt their memory [5]. Steady noises do not seem to bother adults very much, probably because they habituate to them. However, both children and adults struggle to remember words when changing noises play in the background-especially if the changing noise also has words. This means that that you are less likely to remember what you have read if the TV is on. Even children as old as 12 have trouble remembering when the changing sounds do not have words-like jazz music. In other words, all noises disrupt memory when we are young, but different noises become easier to ignore as we get older. This suggests that as we get older, our brains become better at controlling which sounds get our attention. Once we control what our brains pay attention to, we are better at listening and learning through noise.

\section{USE YOUR EYES TO HELP YOU HEAR}

A very important listening trick is to look at important sounds. Looking at something helps us pay attention to it. This will help us separate the important sound from the noise. We can also use the shape of someone's lips as a clue to the sound they are saying. Ask your friend to say the words "dark" and "mark" without making sound. Notice how their lips come together to make the "m" sound? People who are good at using these lip-reading clues are also better at understanding speech in noise. 


\section{CONCLUSION}

Noise makes it difficult to listen and learn. Children have an especially hard time listening and learning in noise because their auditory systems are still developing. However, scientists have discovered some tricks that help us hear better: (1) make important sounds louder and noise quieter, (2) find out where the important sounds are coming from, and (3) look at the important sounds.

\section{SOUND DEMO}

Listen to this sound demo without headphones. Can you tell what story the teacher is reading? Now put on headphones. Do you notice how the teacher moves around the classroom but the noise stays still. Locating the teacher helps us pick out her voice and understand the line from "Jack and the Beanstalk."

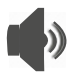

\section{ACKNOWLEDGMENTS}

This work was supported by grants from NIH/NIDCD R01 DC013591 and NIH/NIGMS P20 GM109023. The authors would like to thank Dr. Hans Packer for help with development of the figures. They would also like to thank Dr. G. Chris Stecker for making the sound demo from sound files provided by Calandruccio et al. [7]. They also thank those who assisted in the translation of the articles in this Collection to make them more accessible to kids outside English-speaking countries, and for the Jacobs Foundation for providing the funds necessary to translate the articles. For this article, Tieme Janssen made the Dutch translation.

\section{REFERENCES}

1. Spratford, M., Walker, E. A., and McCreery, R. W. 2019. Use of an application to verify classroom acoustic recommendations for children who are hard of hearing in a general education setting. Am. J. Audiol. 28:927-34. doi: 10.1044/2019_AJA-19-0041

2. Muenssinger, J., Stingl, K. T., Matuz, T., Binder, G., Ehehalt, S., and Preissl, H. 2013. Auditory habituation to simple tones: reduced evidence for habituation in children compared to adults. Front. Hum. Neurosci. 7:377. doi: 10.3389/fnhum.2013.00377

3. Hall, J. W. III, Grose, J. H., Buss, E., and Dev, M. B. 2002. Spondee recognition in a two-talking masker and a speech-shaped noise masker in adults and children. Ear Hear. 23:159-65. doi: 10.1097/00003446-200204000-00008

4. Nakajima, M., and Halassa, M. M. 2017. Thalamic control of functional cortical connectivity. Curr. Opin. Neurobiol. 44:127-31. doi: 10.1016/j.conb.2017.04.001 
5. AuBuchon, A. M., McGill, C. I., and Elliott, E. M. 2019. Auditory distraction does more than disrupt rehearsal processes in children's serial recall. Mem. Cogn. 47:738-48. doi: 10.3758/s13421-018-0879-4

6. McCreery, R. W., Walker, E., Spratford, M., Lewis, D., and Brennan, M. 2019. Auditory, cognitive, and linguistic factors predict speech recognition in adverse listening conditions for children with hearing loss. Front. Neurosci. 13:1093. doi: 10.3389/fnins.2019.01093

7. Calandruccio, L., Leibold, L. J., and Buss, E. 2016. Linguistic masking release in school-age children and adults. Am. J. Audiol. 25:34-40. doi: 10.1044/2015_AJA-15-0053

SUBMITTED: 31 October 2019; ACCEPTED: 09 July 2020; PUBLISHED ONLINE: 25 August 2020.

EDITED BY: Jessica Massonnie, Department of Psychology and Human Development, Institute of Education, University College London, United Kingdom

CITATION: AuBuchon AM and McCreery RW (2020) When Choosing NOT to Listen Helps You Hear and Learn. Front. Young Minds 8:104. doi: 10.3389/frym.2020.00104

CONFLICT OF INTEREST: The authors declare that the research was conducted in the absence of any commercial or financial relationships that could be construed as a potential conflict of interest.

COPYRIGHT (c) 2020 AuBuchon and McCreery. This is an open-access article distributed under the terms of the Creative Commons Attribution License (CC BY). The use, distribution or reproduction in other forums is permitted, provided the original author(s) and the copyright owner(s) are credited and that the original publication in this journal is cited, in accordance with accepted academic practice. No use, distribution or reproduction is permitted which does not comply with these terms.

\section{YOUNG REVIEWERS}

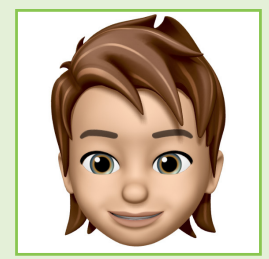

\section{IAGO, AGE: 13}

My name is lago and I am in seventh grade. My favorite subjects are writing, math, social studies, and science. My hobbies are acting, D\&D, and fake-sword fighting. I think it is important for scientists to write for children, so that kids can learn how to think critically and ask questions about how the world works. My mom and dad are "mad" scientists because they stuck a playing card in a brain for a magic trick-good thing the brain was made of Jell-O!

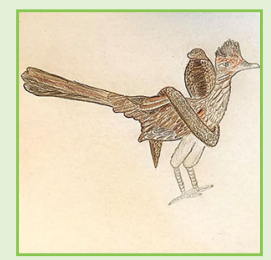

\section{ROADRUNNERS \& COBRAS, AGES: $10-11$}

We are a creative class of fifth graders who are eager to learn more about the world. We have thoroughly enjoyed thinking creatively about this article, and learning more about something that we encounter every day: noise. We have had a fun experience being part of Frontiers for Young Minds! 


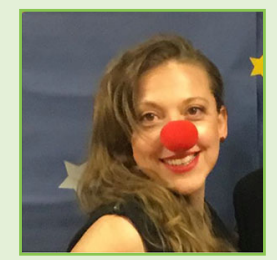

\section{AUTHORS}

\section{ANGELA M. AUBUCHON}

Angela AuBuchon's research goal is to understand how people remember important information (and ignore not-so-important information) in order to solve a problem. To learn more about Angela's research, follow her lab aBoysTownWMLL on Facebook. When Angela is not doing research, she visits local schools to teach students about neuroscience. Her favorite lesson is to help students dissect sheep brains. She is also the cheerleading coach at Platteview High School in Springfield, Nebraska. Go Trojans! *angela.aubuchonaboystown.org

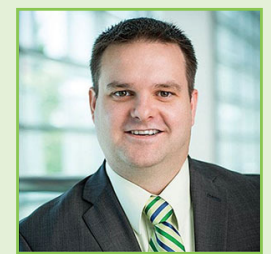

\section{RYAN W. MCCREERY}

Ryan McCreery is a scientist who works to help children who have hearing loss to listen and learn. Find out about Ryan's research @APCLaboratory on Facebook. Ryan is the Director of Research at Boys Town National Research Hospital and the proud father of three wonderful children, Liam, Anna, and Charlotte, and two dogs, Lola and JoJo. 